\title{
PERGAMON
}

www.elsevier.com/locate/watres

\section{EFFECTS OF HUMIC SUBSTANCE CHARACTERISTICS ON UF PERFORMANCE}

\author{
CHENG-FANG LIN ${ }^{1 * M}$, TZE-YAO LIN $^{1}$ and OLIVER J. HAO ${ }^{2 \mathrm{M}}$ \\ ${ }^{1}$ Graduate Institute of Environmental Engineering, National Taiwan University, Taipei, Taiwan, \\ Republic of China and ${ }^{2}$ Department of Civil Engineering, University of Maryland, College Park, \\ MD 20742, USA
}

(First received 1 November 1998; accepted in revised form 1 June 1999)

\begin{abstract}
The role of humic substances in general and hydrophobicity of humic substances in particular on membrane permeate flux is unclear. The main goal of the present study is to evaluate the effect of fractionated humic substances on ultrafiltration (UF) performance. A commercial humic solution was subjected to a hydrophobic resin for fractionation of the hydrophobic and hydrophilic fraction. These fractions were further fractionated into different molecular wight groups, using gel filtration chromatography. The hydrophobic fraction accounts for $85 \%$ organic carbon recovered and has a significantly high THM (trihalomethane) formation potential, or $190 \mu \mathrm{g} / \mathrm{mg} \mathrm{C}$. The hydrophilic fraction exhibits the worst flux decline despite little solute rejection. The results of molecular weight fractionation of both hydrophobic and hydrophilic fractions further indicate that those molecules with the largest molecular weight $(6.5-22.6 \mathrm{kDa})$ exhibit the worst flux decline. The UF system evaluated is unable to remove a significant portion of THM precursors, resulting in potentially high THMs in the permeate. The use of powdered activated carbon (PAC) for the pretreatment of hydrophobic/ hydrophilic humic substances or in an integrated PAC-UF system exhibits an enhanced membrane fouling. (C) 2000 Elsevier Science Ltd. All rights reserved
\end{abstract}

Key words - ultrafiltration, humic acids, hydrophobicity, molecular weight, activated carbon, flux

\section{INTRODUCTION}

Some of the natural organic matter (NOM) present in raw water will form carcinogenic byproducts during disinfection process. For example, Krasner et al. (1996) indicate that humic acids of the NOM have the highest relative THMFP (trihalomethane formation potential); fulvic and hydrophilic acids show comparable THM (trihalomethane) and organic halide formation potentials; and hydrophobic neutral solutes exhibit a much lower THMFP. Also, the assimilable organic carbon present in the NOM may be responsible for bacterial regrowth potential in distribution systems (Noble et al., 1996). As a result, removal of NOM in general and DBP (disinfection-by-products) precursors in particular is of significant importance in meeting the stringent DBP regulations proposed in the near future.

Recently, different membrane processes have received worldwide applications at least in small systems because of lower membrane costs, simplicity of operation, and development of higher flux membranes with low fouling potentials (Adham et

*Author to whom all correspondence should be addressed. Tel.: + 886-2-2362-7427; fax: + 86-2-2392-7653; e-mail: cflin@ccms.ntu.edu.tw al., 1996). Unfortunately, the ultrafiltration (UF) system, due to its high membrane-molecular-weightcutoff, may not be effective for removal of DBP precursors (Laine et al., 1993; Jacangelo et al., 1995), although it is efficient in reducing turbidity, particles, suspended solids, total coliforms (Jacangelo et al., 1989), hydrocarbons (Elmaleh and Ghaffor, 1996) as well as oil and grease (Santos and Wiesner, 1997).

In order to further enhance UF removal capability of DBP precursors, the use of PAC (powdered activated carbon) in conjunction with different UF systems has been successfully demonstrated for removal of synthetic organic chemical (3,4,6-trichlorophenol) and NOM at bench scale (Laine et al., 1990) and at pilot plants (Adham et al., 1991; Jacangelo et al., 1995). For example, at PAC dosage of $90 \mathrm{mg} / \mathrm{l}$, removals as high as $97 \%$ of simulated distribution system THM could be achieved (Jacangelo et al., 1995). Other investigators have also reported the effectiveness of addition of inorganic particles for enhancing contaminant removal in membrane systems, e.g., iron oxide for NOM removal (Chang and Benjamin, 1996; Chang et al., 1998) and $\mathrm{MnO}_{2}$ for increased rejection of solids (Al-Malack and Anderson, 1997). Unfortunately, many studies also 
indicate significant membrane fouling problems either with the use of PAC-pretreatment UF systems or addition of PAC in combined PAC-UF systems.

The gross parameter of DOC (dissolved organic carbon) was often used in most membrane studies to evaluate NOM removal efficiency. Few investigators considered the important characteristics of the NOM in terms of molecular weight distribution, hydrophobic/hydrophilic components, and anionic/ cationic/non-ionic fractions for determining UF performance. For example, if $\mathrm{UF}$ is unable to remove anionic fraction of the NOM, the permeate may exhibit a higher THMFP as well as high biodegradable DOC (Afcharian et al., 1997). The effect of apparent molecular weight (AMW) fractions on UF performance has been partially addressed (Lin et al., 1999); the fraction with the largest AMW (6.5-22.6 kDa) exhibits the worst flux decline with the best permeate quality, whereas the smallest AMW fraction (160-650 Da) exerts little effect on flux decline. Although, the UF system is able to remove a significant portion of THM precursors present in larger MW fractions, the permeate THM yield ( $\mu \mathrm{g}$ THMs/mg C) is still high.

This paper presents the results of the effects of hydrophobic and hydrophilic fractions of humic substances on UF performance. The first phase of the present study was to characterize the different fractions of a commercial humic product with respect to their THMFPs. These fractions included hydrophobic and hydrophilic fractions and AMW subfractions of each hydrophobic/hydrophilic fraction. In the second phase study, these fractions were fed into an UF system to observe their effects on membrane permeate flux. Additionally, different factions were initially pretreated with PAC or dosed with PAC in a combined PAC-UF system to observe the role of PAC in reducing membrane flux, if any.

\section{MATERIALS AND METHODS}

\section{Feed water}

The diluted humic acid solution (sodium salt, Aldrich) and its different fractions with respect to AMW and hydrophobicity were used as the feed water. A stock solution (DOC $\approx 50 \mathrm{mg} / \mathrm{l}$ ) was prepared by dissolving $150 \mathrm{mg}$ humic acid in 11 deionized water (Milli-Q), and filtering through $0.45 \mu \mathrm{m}$ cellulose nitrate membrane filter (Whatman). Additionally, PAC-treated humic acid fractions were also used as UF feed solutions. All these solutions were supplemented with $\mathrm{NaCl}$ to maintain a relatively similar conductivity $(\approx 1500 \mu \mathrm{mho} / \mathrm{cm})$ to the extent possible, adjusted $\mathrm{pH}$ to 7 with $\mathrm{HCl}$ and/or $\mathrm{Na}_{2} \mathrm{HPO}_{4}\left(10^{-3} \mathrm{M}\right)$, and diluted to DOC about $5 \mathrm{mg} / \mathrm{l}$.

Fractionation of humic acid

The DAX-8 hydrophobic resin $(0.24-0.32 \mathrm{~mm}$ size, $160 \mathrm{~m}^{2} / \mathrm{g}$ mean surface area, $0.023 \mu \mathrm{m}$ mean pore diameter, Supelite) was initially washed with methanol and deionized water before packing in a $35 \mathrm{~cm}$ column (C 16 70, Pharmacia Biotech, Sweden). The acidified stock

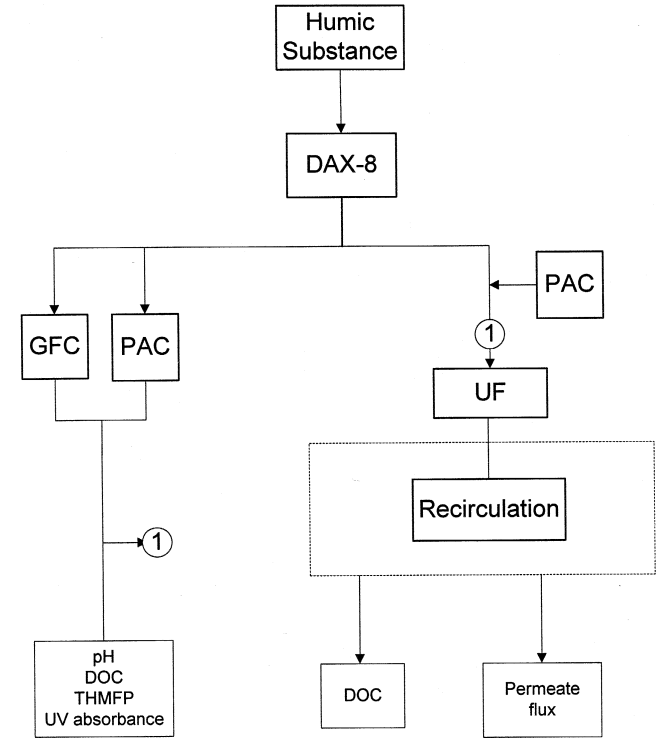

Fig. 1. Schematic diagram of the overall experimental approach.

humic solution $(\mathrm{pH} \mathrm{2})$ was pumped into the column at the rate of $5-6 \mathrm{ml} / \mathrm{min}$ for the collection of hydrophilic fraction, whereas the hydrophobic fraction was collected after the resin was subsequently eluted with $0.1 \mathrm{M} \mathrm{NaOH}$. These two collected fractions were further subject to gel filtration chromatography (GFC) for AMW fractionation. The materials used and procedures for GFC have been described elsewhere (Lin et al., 1999). Each of the hydrophobic and hydrophilic fraction collected as well as their four separate AMW fractions was analyzed for DOC, UV absorbance, and THMFP.

$P A C$

PAC obtained from Sigma was used either for sample pretreatment or as an additive in combined PAC-UF studies. The BET surface area is approximately $730 \mathrm{~m}^{2} / \mathrm{g}$ with the average pore diameter $0.025 \mu \mathrm{m}$. The size ranges from 10 to $150 \mu \mathrm{m}$ with $D_{50}=50 \mu \mathrm{m}$.

\section{UF operation}

A single hollow fiber membrane (hydrophobic with negatively charged polysulfone; A/G Technology) with a length of approximately $30 \mathrm{~cm}$ and diameter $1 \mathrm{~mm}$ was used. The nominal molecular-weight-cutoff is $100 \mathrm{kDa}$. The crossflow mode was operated in the UF system by recirculating only concentrate stream to simulate the actual UF plant configuration. In a few experiments, the system was also operated by discarding both permeate and concentrate streams to maintain a relatively constant feed DOC concentration. For the combined PAC-UF system, PAC at $40 \mathrm{mg} / 1$ was directly added into the feed tank, mixed for $24 \mathrm{~h}$, and the mixture was then subject to the UF system.

Throughout the experiments, the transmembrane pressure was maintained at about $160 \mathrm{kPa}$, and permeate flux was monitored. Permeate of some experiments was analyzed for DOC. The schematic diagram of the overall experiment is illustrated in Fig. 1.

\section{Analysis}

DOC was analyzed on filtered samples $(0.45 \mu \mathrm{m})$ in an organic carbon analyzer (O.I. model 700). UV absorbance was measured in a UV/VIS spectrophotometer (Jasco, PTL-3965) at the wavelength $254 \mathrm{~nm}$. The procedures for 
Table 1. Characteristics of fractionated and unfractionated humic substances

\begin{tabular}{lcc}
\hline Parameter & DOC $\mathrm{mg} / \mathrm{l}$ & THMFP $/$ DOC $\mu \mathrm{g} / \mathrm{mg}$ \\
\hline Unfractionated & 50.7 & 165 \\
Hydrophobic & 39.2 & 190 \\
Hydrophilic & 6.5 & 130 \\
\hline
\end{tabular}

the THMFP test followed the section 5710B of the Standard Methods (APHA, 1987): $\mathrm{pH}=7.0, T=25^{\circ} \mathrm{C}$, and a $\mathrm{Cl}_{2}$ residual of $3-5 \mathrm{mg} / \mathrm{l}$ after 7 days. Four THMs were quantified in a Hewlett Packard GC unit (model 5892 II) with a fused silica capillary column and an electron capture detector.

Occasionally, membrane specimen was prepared for morphological observation using a Hitachi S520 scanning electron microscope (SEM). The method was similar to those described in Lin et al. (1993). The SEM was operated at $20 \mathrm{keV}$ accelerating voltage.

\section{RESULTS AND DISCUSSION}

\section{Characteristics of humic acid fractionation}

The THMFP characteristics of hydrophobic and hydrophilic fractions as well as unfractionated humic substances are shown in Table 1. The overall recovery of organic carbon from the DAX-8 is about $90 \%$, and the majority of the recovered DOC of the commercial humic product is present in the hydrophobic fraction $(86 \%)$. For comparison, Nilson and DiGiano (1996) reported a recovery of almost equal DOC portion of hydrophobic and hydrophilic fractions in natural waters, using XAD8 resins, while Collins et al. (1986) found that hydrophilic portion accounted for $65 \%$ of the sample DOC. The conflicting information is not unexpected since the commercial humic acids may not represent actual humic materials in natural environment (Malcolm and MacCarthy, 1986), where humic components also vary with season and environmental source, among other factors. The ratio of THMFP/DOC for hydrophobic fraction is the highest $(190 \mu \mathrm{g} / \mathrm{mg})$, but that of hydrophilic fraction is also high, or $130 \mu \mathrm{g} / \mathrm{mg}$; these values are much higher than those reported values from natural water samples, e.g., 55-114 $\mu \mathrm{g} / \mathrm{mg}$ (Collins et al., 1986) and 59-110 $\mu \mathrm{g} / \mathrm{mg} \mathrm{C}$ for eight surface water sources (Krasner et al., 1996). The high reactivity of hydrophilic fraction to from THMs is of significance in determining UF permeate quality.

The THMFP characteristics of humic substances and their fractions after $24 \mathrm{~h}$ contact with PAC $(40 \mathrm{mg} / \mathrm{l})$ are shown in Table 2 . The DOC removal efficiency $(20-23 \%)$ is similar to all three cases of unfractionated, hydrophobic, and hydrophilic fractions. PAC indeed removes some of THM precursors since the ratios of THMFP/DOC (90-105 $\mu \mathrm{g} /$ $\mathrm{mg}$ ) are much lower than those values shown in Table 1. Particularly, UV absorbance at $254 \mathrm{~nm}$ in hydrophobic fraction has been significantly reduced, resulting in a reduction of approximately $45 \%$ of THM yield. Nonetheless, the PAC-treated factions still contain high THM yields as UV/DOC ratios are relatively high.

The hydrophobic and hydrophilic fractions as well as unfractionated humic substances were further subjected to AMW classification. The AMW distribution for unfractionated humic substances is shown in Fig. 2, which indicates the highest DOC (16.5 mg/l) and UV absorbance (1.2) occurring at about $14 \mathrm{kDa}$. The results of these AMW fractions with respect to several important water quality parameters are shown in Tables 3-5. For all these three cases, the trend of DOC distribution and THMFP/DOC yield among different AMW groups is quite similar, i.e., the DOC content and THMFP/DOC ratio present in the largest AMW fraction $(6.5-22.6 \mathrm{kDa}$; A-1, B-1 and C-1 in Tables $3-5$, respectively) are the highest as compared to those values in other AMW fractions. Further, the DOC contents of smaller fractions $(<2.2 \mathrm{kDa})$ make up less than $44 \%$ of the commercial humic substances. This finding is in contrast to some reports that the majority of the THM precursors are present in the AMW fraction less than 1 kDa (e.g., Amy et al., 1992). Again, these THM yield values are much higher than those of natural water samples (Nilson and DiGiano, 1996).

In general, those fractions with lower AMW exhibit lower color index and long chain aliphatic carbons with lower carbohydrate content (Newcombe et al., 1997a). Also, samples with high ratios of $\mathrm{UV} / \mathrm{DOC}$ as in our cases indicate a high reactivity to form THMs (Krasner et al., 1996). Since UF systems with a high molecular-weight-cutoff membrane cannot remove all humic substances resulting in some fractions remaining including those of different AMW groups and hydrophobic/hydrophilic residuals, the data in these tables clearly demonstrate the fact that the UF permeate may still contain potential THMs. Furthermore, if the low AMW fraction, which can not be removed by the UF systems, is present in a large quantity, it may contribute to the so-called assimilable organic carbon and, hence, it is certainly responsible for bacterial regrowth potential in distribution systems. Incidentally, the low-

Table 2. Characteristics of PAC-treated humic substances with initial DOC $=5 \mathrm{mg} / 1$ and PAC $=40 \mathrm{mg} / 1$

\begin{tabular}{lcccc}
\hline Classification & UV254 abs & DOC mg/l & UV/DOC 1/mg & THMFP/DOC $\mu$ g/mg \\
\hline Unfractionated & 0.323 & 4.02 & 0.080 & 100 \\
Hydrophobic & 0.254 & 3.91 & 0.065 & 105 \\
Hydrophilic & 0.312 & 3.85 & 0.081 & 90 \\
\hline
\end{tabular}




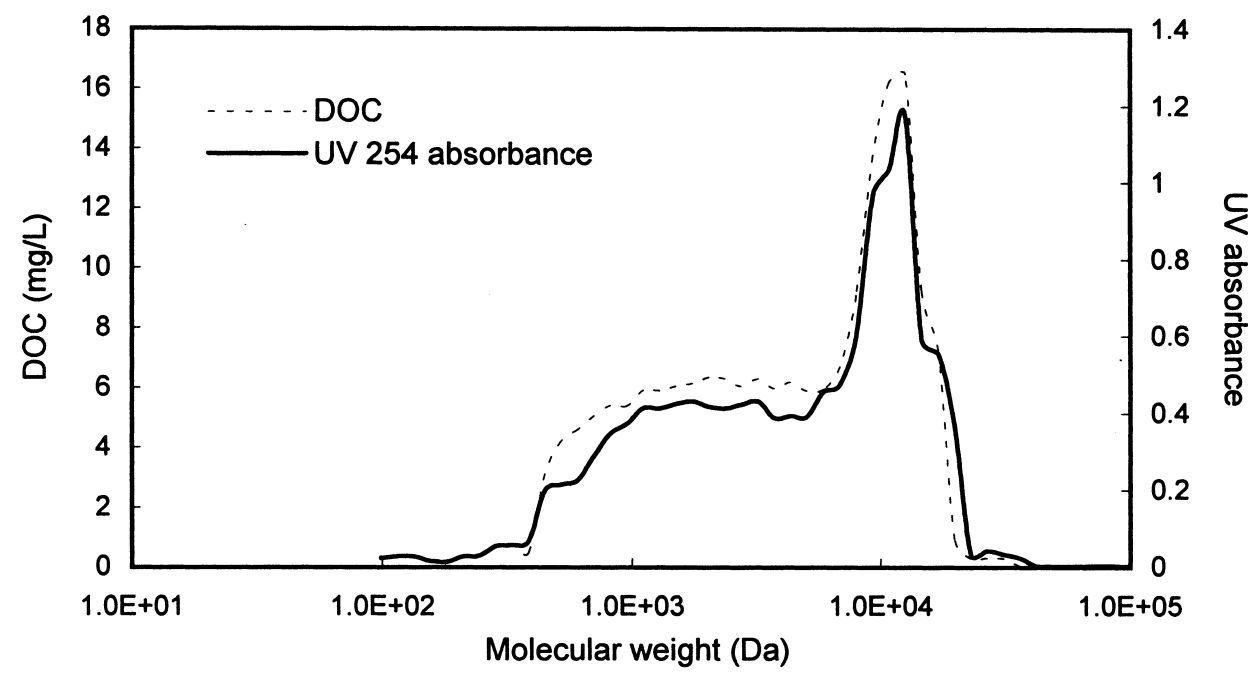

Fig. 2. GFC chromatograms of commercial humic substances.

est AMW fraction has the highest UV/DOC reading among fractionated groups for all three cases, ranging from 0.075 to $0.094 \mathrm{l} / \mathrm{mg}$.

\section{Effect of humic substance hydrophobicity}

The normalized permeate fluxes for these fractions at a constant feed DOC $(5 \mathrm{mg} / \mathrm{l})$ are shown in Fig. 3(a). The initial values of all flux data including those presented later were relatively constant, or $330 \pm 15 \mathrm{l} / \mathrm{m}^{2} \mathrm{~h}$. The NOM-free water, due to its relatively high conductivity, exhibits slightly more than $10 \%$ flux decline after 30 -h operation. The hydrophilic fraction represents the worst flux decline as only $48 \%$ of the original flux remains after 30 h. However, Nilson and DiGiano (1996) reported that hydrophilic NOM exhibited little permeate flux decline and hydrophobic NOM was responsible for nearly all permeate flux decline in a nanofiltration unit.

After PAC pretreatment of these fractions, the hydrophilic fraction still exhibits the worst flux decline (Fig. 3(b)). Furthermore, the membrane permeate flux is worse for all three cases of PACtreated humic substances (e.g., drop to $38 \%$ of the original flux after 30 -h operation for hydrophilic fraction), despite the fact that the feed DOC concentrations are less than $5 \mathrm{mg} / \mathrm{l}$ (Table 2). It is unclear as to the reason for the enhanced membrane fouling with the PAC-pretreated fractions. Clearly, the interaction between membrane and the remaining PAC-nonadsorbable organic carbon must play a role in facilitating flux decline. Since this system is not a representative of the actual UF operation, the subsequent experiments have all been conducted with recirculating only concentrate stream.

The data of each fraction subject to UF in a recirculating system are shown in Fig. 4, in which the flux results from PAC-pretreated fractions and combined PAC-UF systems are also included for comparison. Both hydrophobic and hydrophilic fractions as well as unfractionated humic substances have a similar flux pattern (i.e., about $60 \%$ of the original flux after 8-h operation); yet DOC removal of the hydrophilic fraction after $8 \mathrm{~h}$ is only $10 \%$ as compared to $30 \%$ for hydrophobic component (Fig. 5). In other words, the degree of membrane fouling in this particular case does not necessarily relate to the extent of DOC removal. The membrane fouling due to hydrophilic component even with little rejection is more of a problem in terms of permeate quality and flux decline.

In all three cases, those feed solutions without PAC addition or PAC- pretreatment exhibit the lowest flux decline (Fig. 4). For both hydrophobic and hydrophilic fractions, the combined PAC-UF system yields the worst flux decline, whereas the PAC-pretreated system yields the largest flux decline for the unfractionated humic substances. Although some studies in combined PAC-UF systems (Adham et al., 1991; Jacangelo et al., 1995), iron oxide-UF systems (Chang and Benjamin, 1996;

Table 3. Characteristics of AMW fractionated humic substances

\begin{tabular}{lrccccc}
\hline Fractionated group & AMW Da & UV254 abs & DOC mg/l & DOC \% & UV/DOC 1/mg & THMFP/DOC $\mu$ g/mg \\
\hline A-1 & $6500-22,600$ & 0.691 & 11.2 & 32 & 0.062 & 175 \\
A-2 & $2200-6500$ & 0.648 & 8.9 & 26 & 0.073 & 160 \\
A-3 & $650-2200$ & 0.556 & 7.7 & 22 & 0.072 & 140 \\
A-4 & $180-650$ & 0.512 & 6.8 & 20 & 0.075 & 130 \\
\hline
\end{tabular}


Table 4. Characteristics of AMW fractionationed hydrophobic substances

\begin{tabular}{|c|c|c|c|c|c|c|}
\hline Fractionated group & AMW Da & UV254 abs & $\mathrm{DOC} \mathrm{mg} / 1$ & DOC $\%$ & $\mathrm{UV} / \mathrm{DOC} 1 / \mathrm{mg}$ & THMFP/DOC $\mu \mathrm{g} / \mathrm{mg}$ \\
\hline B-1 & $6500-22,600$ & 0.715 & 12.1 & 36 & 0.059 & 220 \\
\hline B-2 & $2200-6500$ & 0.667 & 8.9 & 27 & 0.075 & 170 \\
\hline B-3 & $650-2200$ & 0.545 & 6.9 & 21 & 0.079 & 155 \\
\hline B-4 & $180-650$ & 0.501 & 5.4 & 16 & 0.094 & 150 \\
\hline
\end{tabular}

Table 5. Characteristics of AMW fractionated hydrophilic substances

\begin{tabular}{lrccccc}
\hline Fractionated group & AMW Da & UV254 abs & DOC mg/l & DOC \% & UV/DOC 1/mg & THMFP/DOC $\mu$ g/mg \\
\hline C-1 & $6500-22,600$ & 0.601 & 9.8 & 33 & 0.061 & 175 \\
C-2 & $2200-6500$ & 0.562 & 7.5 & 26 & 0.075 & 160 \\
C-3 & $650-2200$ & 0.519 & 6.1 & 21 & 0.085 & 140 \\
C-4 & $180-650$ & 0.536 & 6.0 & 20 & 0.089 & 115 \\
\hline
\end{tabular}

Chang et al., 1998), and PAC-pretreatment UF system (Laine et al., 1990) have indicated reduced membrane fouling, other investigators report more flux decline in a PAC-pretreatment nanofiltration system (Nilson and DiGiano, 1996) and combined PAC-UF system (Lin et al., 1999).

The conflicting results may be due to the type and the amount of PAC added (Jacangelo et al.,
1995), type of NOM as well as DOC concentration (Chang et al., 1998), solution chemistry (Braghetta et al., 1997), pH (Chang et al., 1998), and characteristics of the membrane used. It is unclear as to the reason that the addition of PAC in the integrated PAC-UF system affects flux decline. Previously, it has been demonstrated that PAC alone in the deionized water does not affect flux at
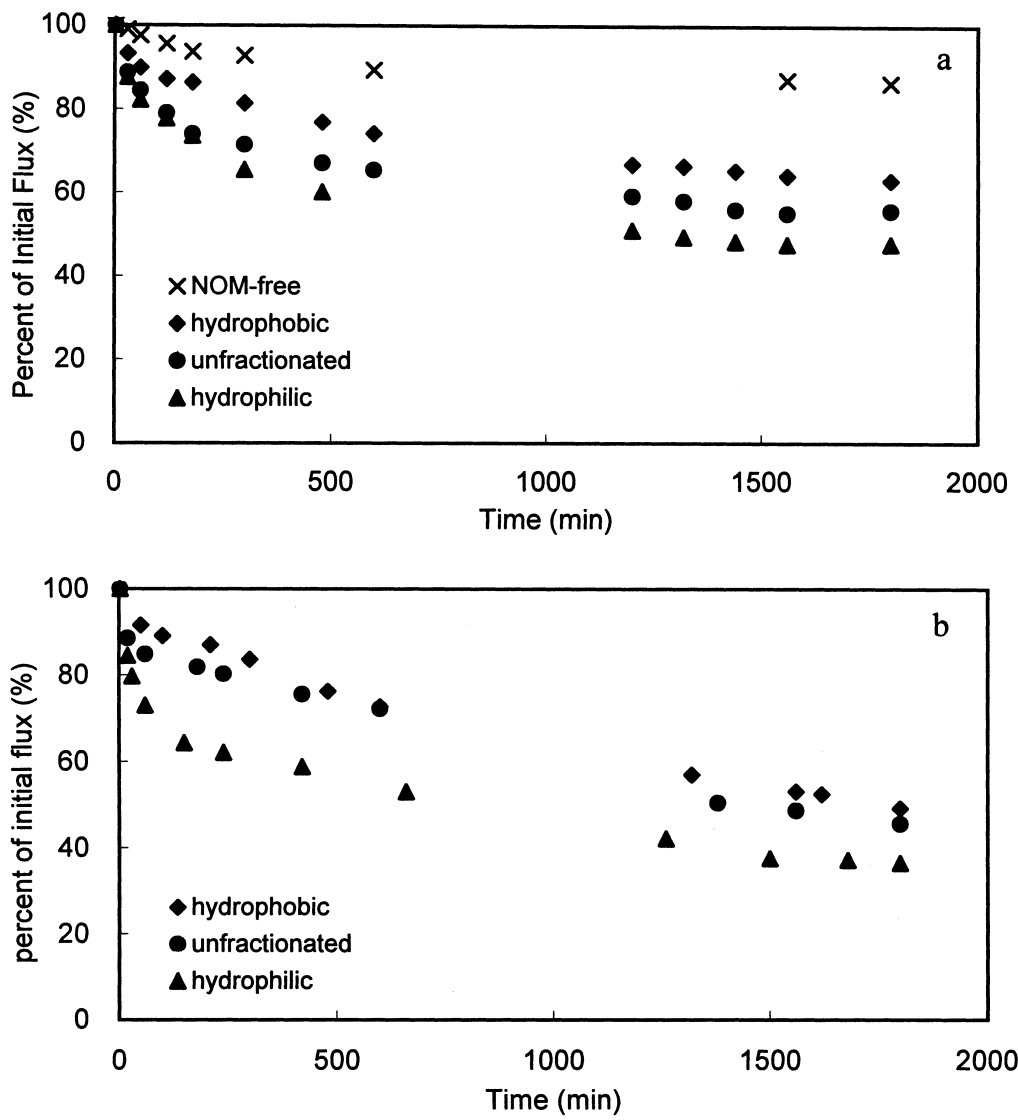

Fig. 3. Permeate flux of unfractionated, hydrophobic, and hydrophilic humic substances operated at the constant feed concentration mode: (a) untreated samples (DOC $=5 \mathrm{mg} / \mathrm{l}$ ) and (b) PAC-treated sample. 

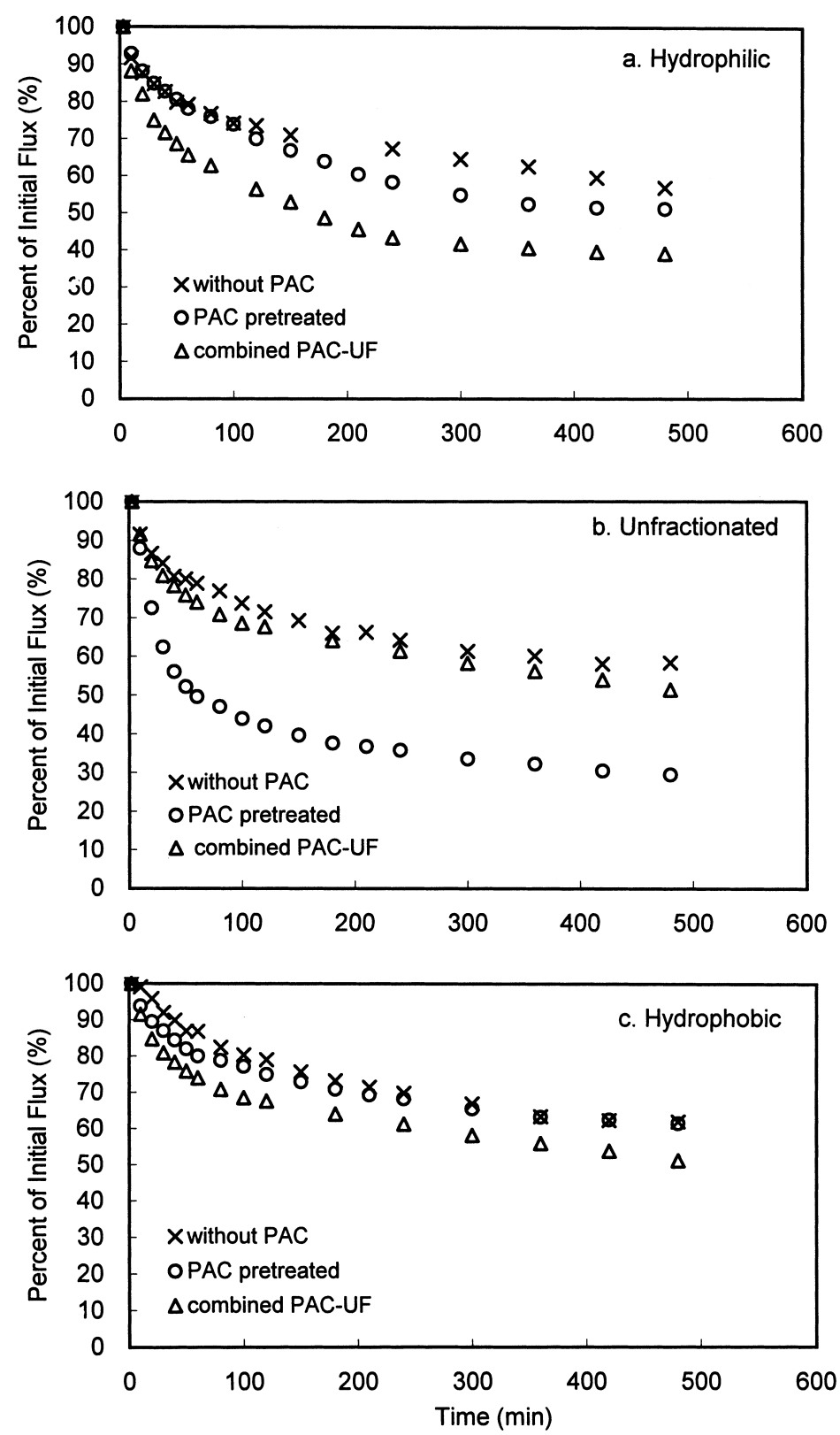

Fig. 4. Permeate flux of unfractionated, hydrophobic, and hydrophilic humic substances operated with only concentrate stream recycling to the feed: (a) hydrophobic, (b) unfractionated and (c) hydrophilic fraction.

all; the flux after $350 \mathrm{~min}$ operation is still the same as the original data (Lin et al., 1999). The high affinity of non-adsorptive humic substances for UF membrane as in the case of PAC-pretreatment as well as the potentially modified carbon surface characteristics resulting from adsorption of organic matter (Newcombe et al., 1997b) may be partially responsible for the observed phenomenon. Further, DOC removal data in Fig. 5 clearly indicate that the PAC-mediated cases all result in enhanced DOC removal. Thus, more adsorbed solutes may in fact explain facilitated membrane fouling and event- ual flux decline. Qualitative information in supporting the membrane fouling is shown in SEM pictures; SEM graph for the clean membrane is included for comparison (Fig. 6(a)). There are noticeable humic substances deposited on the surface of membrane (Fig. 6(b)), and a serious scale problem is present in the PAC-UF system (Fig. 6(c)). In short, the results of the present study demonstrate that the use of this particular PAC either as a pretreatment agent or as an additive in the integrated PAC-UF system is ineffective to alleviate membrane fouling. 

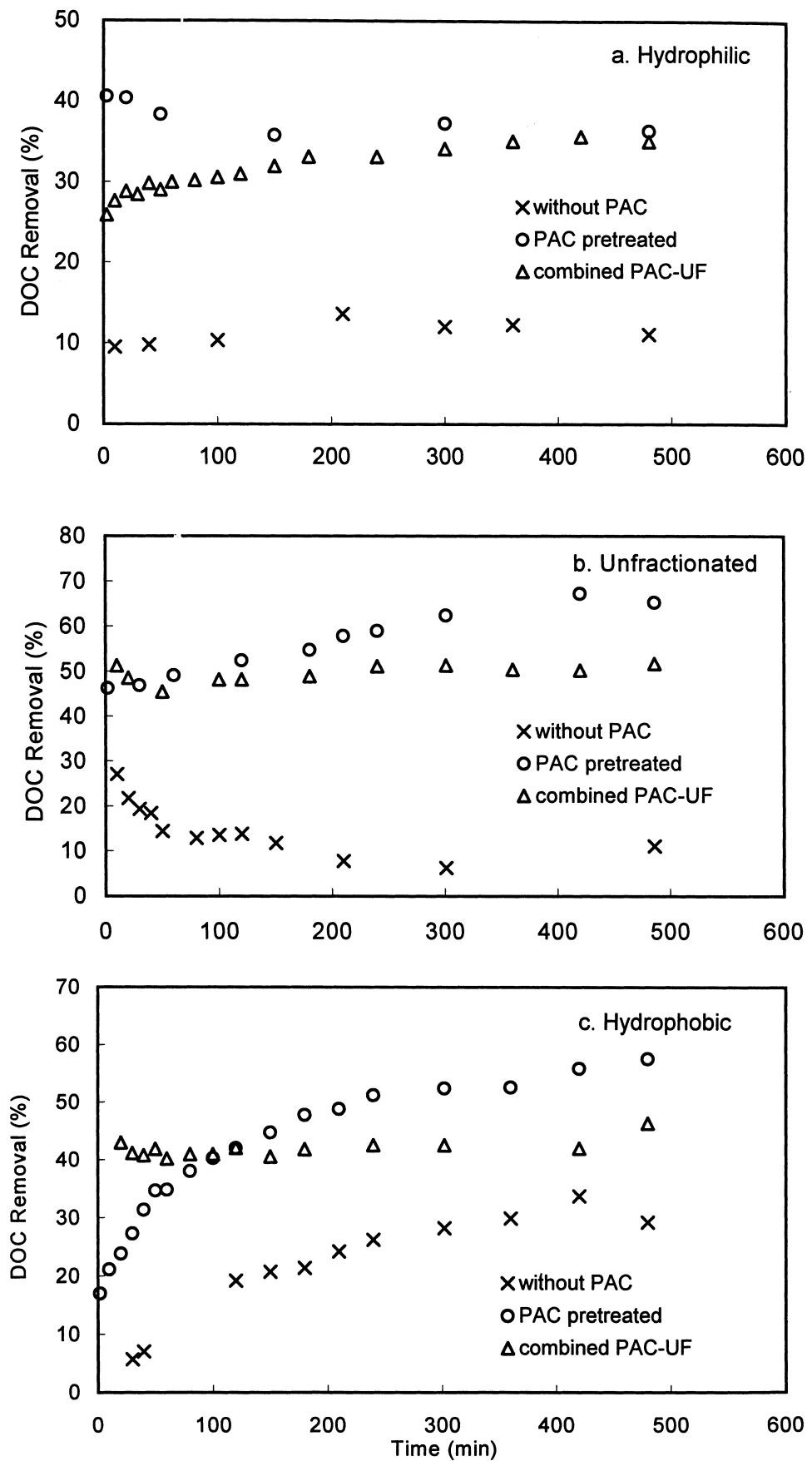

Fig. 5. DOC removal of unfractionated, hydrophobic, and hydrophilic humic substances: (a) hydrophobic, (b) unfractionated and (c) hydrophilic fraction.

It is noted that unfractionated humic substances have the worst flux decline in the PAC-pretreatment system. The humic substances that are not recovered $(10 \%)$ during the resin fractionation may be responsible for the membrane fouling. Incidentally, the flux pattern in Fig. 4 is similar to that of a nanofiltration study of effects of hydrophobic/ hydrophilic fractions isolated from Suwannee River humic substances (Braghetta et al., 1998).

\section{Effect of AMW fractionation}

Each of the AMW fraction of the three cases (unfractionated raw humic substances, hydrophobic, and hydrophilic fractions) was diluted to the same DOC concentration $(5 \mathrm{mg} / \mathrm{l})$ and fed to the UF system to observe AMW effects on permeate flux. The results of membrane flux with respect to AMW factions are shown in Fig. 7. In all cases, the largest AMW fractions (6.5-22.6 kDa; A-1, B-1 and C-1 in 

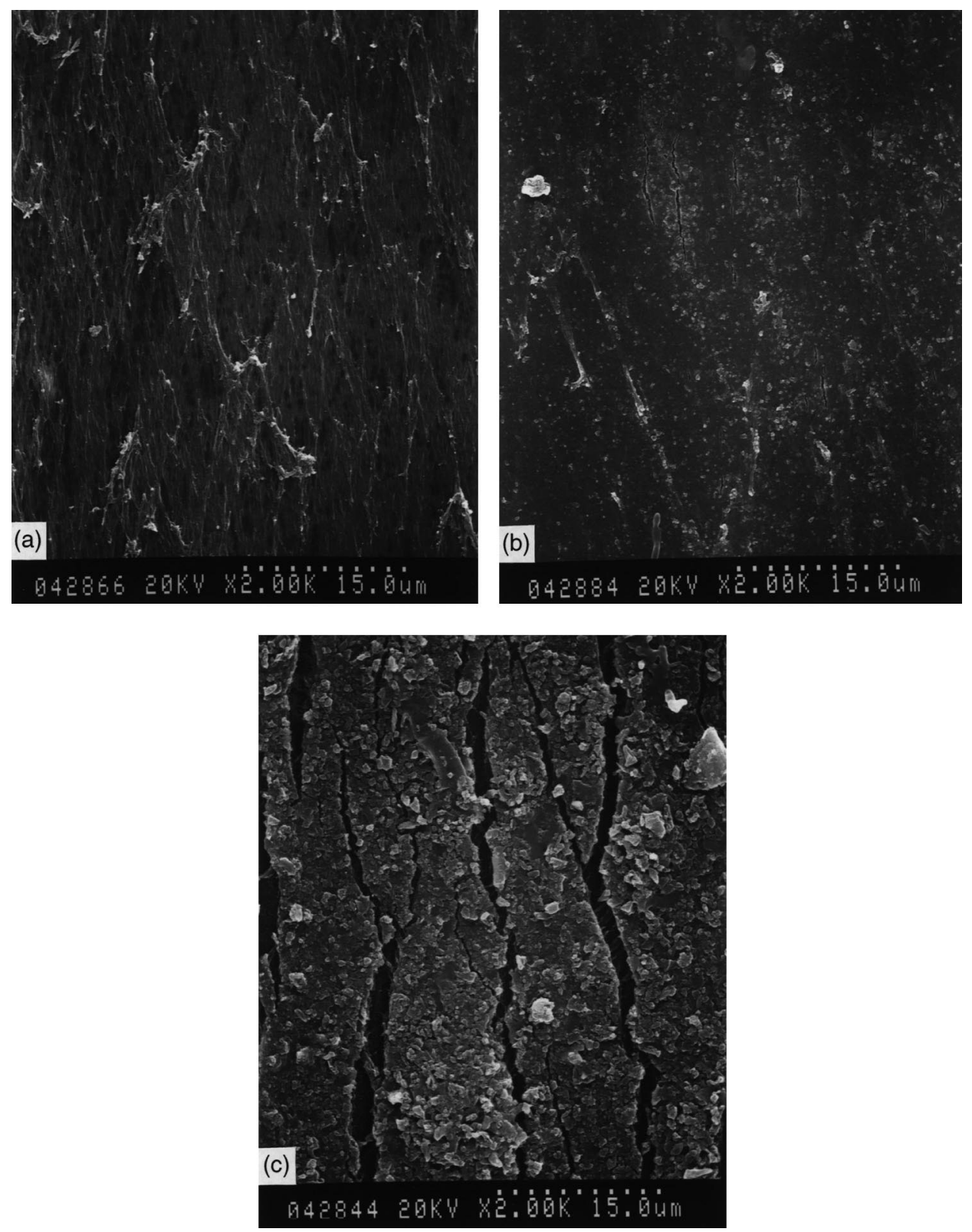

Fig. 6. SEM graphs: (a) clean membrane, (b) unfractionated humic acid and (c) unfractionated humic acid with PAC.

Fig. 7) exert the worst flux decline, and smallest fractions $(<650$ Da) the least flux decline. Previously, it has been demonstrated (Lin et al., 1999) that permeate quality for the unfractionated humic substances is the best in the largest AMW fraction, and DOC removal of this fraction results in irreversible membrane fouling. The organic molecules with smaller AMW fractions could easily be passed through membrane pore size resulting in a lesser membrane fouling and higher permeate DOC. Specifically, data in Tables 3-5 indicate a higher THM yield at these smaller AMW fractions. Thus, the UF system used is ineffective to remove DBP precursors. It is interesting to note that flux decline for both hydrophobic and hydrophilic fractions in the smallest AMW fraction is worse than that of unfractionated humic substances.

\section{CONCLUSIONS}

Unlike natural humic substances, the majority of the DOC of the commercial humic product is present in the hydrophobic fraction. Both hydrophobic and hydrophilic fractions exhibit significantly higher THMFPs. For the unfractionated, hydrophobic, and hydrophilic fractions, the trend of DOC distribution and THMFP/DOC yield among four different AMW groups is quite similar, i.e., the DOC 

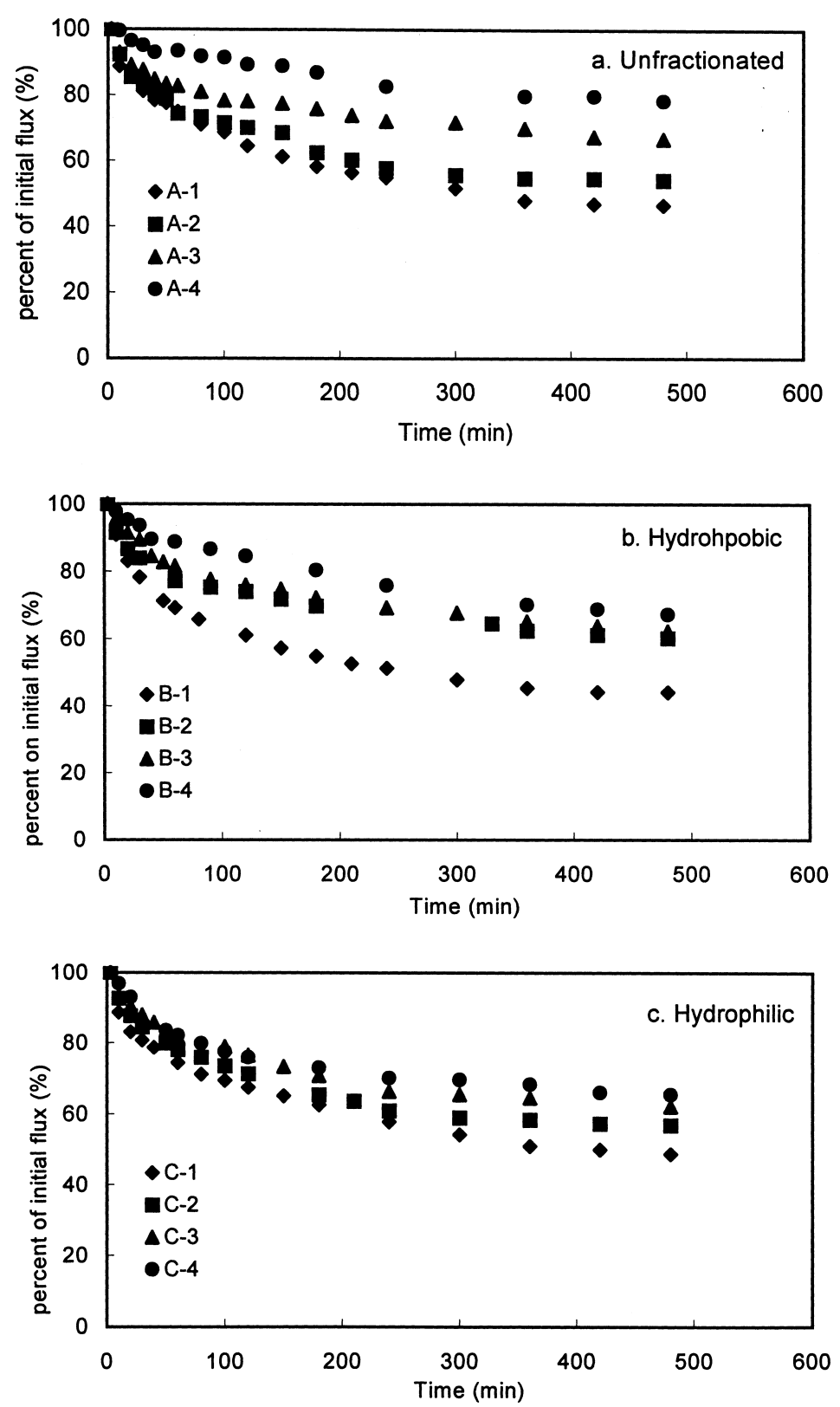

Fig. 7. Permeate flux of molecular wight fractions: (a) unfractionated; (b) hydrophobic and (c) hydrophilic.

content and THMFP/DOC ratio present in the largest AMW fraction $(6.5-22.6 \mathrm{kDa})$ are the highest as compared to those THM yield values in other AMW fractions. Further, the DOC contents of smaller fractions $(<2.2 \mathrm{kDa})$ make up less than $44 \%$ of the commercial humic substances.

Although UF is effective in reducing turbidity, particulates, organics, and bacteria, the results of the present study reaffirm the previous findings in that humic substances are not being removed effectively and these substances also significantly facilitate flux decline. Specifically, the hydrophilic component exhibits more flux decline, despite little rejection of hydrophilic molecules. Consequently, the permeate may still contain a significant high ratio of THM yield ( $\mu \mathrm{g}$ THMs/mg DOC). Further, those DOC groups with the largest AMW fractions $(6.5-22.6 \mathrm{kDa})$ of both hydrophobic and hydrophilic components exhibit the worst flux decline. Even the smallest AMW fractions (160-650 Da) still exert some effects on flux decline, or $65-70 \%$ of the initial flux after $8 \mathrm{~h}$.

The use of PAC for pretreament of hydrophobic and hydrophilic fractions of humic substances, or in an integrated PAC-UF system, in fact, facilitates membrane fouling. 
Acknowledgements - This study was funded by the National Science Council of Republic of China in Taiwan under contract NSC 88-2211-E-002-015. The author $(\mathrm{OJH})$ is grateful to the NSC for providing a visiting appointment (NSC 87-2811-E-002-0004) at the National Taiwan University during which time this study was undertaken.

\section{REFERENCES}

Adham S. S., Snoeyink V. L., Clark M. M. and Bersillon J-L. (1991) Predicting and verifying organics removal by PAC in an ultrafiltration system. J. Am. Water Works. Assoc. 83, 81-91.

Adham S. S., Jacangelo J. G. and Laine J-M. (1996) Characteristics and costs of MF and UF plants. $J$. Am. Water Works. Assoc. 88, 22-31.

Afcharian A., Levi Y., Kiene L. and Scribe P. (1997) Fractionation of dissolved organic matter from surface waters using macroporous resins. Water Res. 31, 2989 2996.

Al-Malack M. H. and Anderson G. K. (1997) Crossflow microflitration with dynamic membranes. Water Res. 31, 1969-1979.

Amy G. L., Sierka R. A., Bedessem J., Price D. and Tan L. (1992) Molecular size distributions of dissolved organic matter. J. Am. Water Works. Assoc. 84, 67-75.

APHA (1987) Standard Methods for the Examination of Water and Wastewater, 17th ed. Am. Public. Health Assoc, Washington, DC.

Braghetta A., DiGiano F. A. and Ball W. P. (1997) Nanofiltration of natural organic matter: $\mathrm{pH}$ and ionic strength effects. J. Environ. Engrg 123, 628-641.

Braghetta A., DiGiano F. A. and Ball W. P. (1998) NOM accumulation at NF membrane surface: impact of chemistry and shear. J. Environ. Engrg 124, 1087-1098.

Chang Y. and Benjamin M. M. (1996) Iron oxide adsorption and UF to remove NOM and control fouling. $J$. Am. Water Works. Assoc. 88, 74-88.

Chang Y-J., Choo K-H., Benjamin M. M. and Reiber S. (1998) Combined adsorption-UF process increases TOC removal. J. Am. Water Works. Assoc. 90, 90-102.

Collins M. R., Amy G. L. and Steelink C. (1986) Molecular weight distribution, carboxylic acidity, and humic substances content of aquatic organic matter: implications for removal during water treatment. Environ. Sci. Technol. 20, 1024-1032.

Elmaleh S. and Ghaffor N. (1996) Upgrading oil refinery effluents by cross-flow ultrafiltration. Water Sci. Technol. 34, 231-238.
Jacangelo J. G., Laine J-M., Cummings E. W. and Adham S. S. (1995) UF with pretreatment for removing DBP precursors. J. Am. Water Works. Assoc. 87, 100112.

Jacangelo J. G., Aieta E. M., Carns K. E., Cummings E. W. and Mallevialle J. (1989) Assessing hollow-fiber UF for particulate removal. J. Am. Water Works. Assoc. 81, $68-75$.

Krasner S. W., Croue J-P., Buffle J. and Perdue E. M. (1996) Three approaches for characterizing NOM. $J$. Am. Water Works. Assoc. 88, 66-79.

Laine J-M., Clark M. M. and Mallevialle J. (1990) Ultrafiltration of lake water: effect of pretreatment on the partitioning of organics, THM formation potential, and flux. J. Am. Water Works. Assoc. 82, 82-87.

Laine J-M., Jacangelo J. G., Cummings E. W., Carns K. E. and Mallevialle J. (1993) Influence of bromide on low-pressure membrane filtration for controlling DBPs in surface waters. J. Am. Water Works. Assoc. 85, 8799.

Lin T-T., Lin C-F., Wei W-C. J. and Lo S-L. (1993) Mechanisms of metal stabilization in cementitious metals: interaction of tricalcium aluminate and copper oxide/hydroxide. Environ. Sci. Technol. 27, 1312-1316.

Lin C-F., Huang Y-J. and Hao O. J. (1999) UF processes for removing humic substances: effect of molecular weight fractions and PAC treatment. Water Res. 33, 1252-1264.

Malcolm P. L. and MacCarthy P. (1986) Limitations in the use of commercial humic acids in water and soil research. Environ. Sci. Technol. 20, 904-911.

Newcombe G., Drikas M., Assemi S. and Beckett R. (1997a) Influence of characterised natural organic material on activated carbon adsorption-I: characterisation of concentrated reservoir water. Water Res. 31, 965-972.

Newcombe G., Drikas M. and Beckett R. (1997b) Influence of characterised natural organic material on activated carbon adsorption-II: effect of pore volume distribution and adsorption of 2-methylisoborneol Water Res. 31, 1065-1073.

Nilson J. A. and DiGiano F. A. (1996) Influence of NOM composition on nanofiltration. J. Am. Water Works. Assoc. 88, 53-66.

Noble P. A., Clark D. L. and Olson B. H. (1996) Biological stability of groundwater. J. Am. Water Works. Assoc. 88, 87-96.

Santos S. M. and Wiesner M. R. (1997) Ultrafiltration of waste generated in oil and gas production. Water Environ. Res. 69, 1120-1127. 